\title{
Compliance Matrices for Cracked Bodies
}

$($ NASA-CR-179478) COAELIANCE MATEICES FOR CRACKED BODIES Final beport fCleveland State Uni .) $_{i}: 8 \mathrm{p}$ CSCL $20 \mathrm{~K}$

R. Ballarini

Cleveland State University

Cleveland, Ohio

July 1986

Prepared for

Lewis Research Center

Under Grant NCC 3-46 
COMPLIANCE MATRICES FOR CRACKED BODIES

\author{
R. Ballarini \\ Cleveland State University \\ Department of Civil Engineering \\ Cleveland, Ohto 44115 \\ SUMMARY
}

An algorithm is presented which can be used to develop compliance matrices for cracked bodies. The method relies on the numerical solution of singular integral equations with Cauchy-type kernels and provides an efficient and accurate procedure for relating applied loadings to crack opening displacements. The algorithm should be of interest to those performing repetitive calculations in the analysis of experimental results obtained from fracture specimens.

\title{
INTRODUCTION
}

Two dimensional problems in linear elastic fracture mechanics are of ten reduced to a singular integral equation (or system of integral equations) of the form

$$
\int_{-1}^{1} \frac{f(t) d t}{t-x}+\int_{-1}^{1} k(x, t) f(t) d t=g(x) \quad-1<x<1
$$

where $f(t)$ is a function to be determined, and $K(x, t)$ and $g(x)$ are known functions related to the geometry of the cracked body and the loading on the crack surface(s): respectively. The function $f(t)$, which is called the dislocation density, is the slope of the crack profile, and, if the crack is closed at its tips, satisfies the consistency condition

$$
\int_{-1}^{1} f(t) d t=0
$$

In this paper an algorithm is presented which can be used to develop a compliance matrix for a cracked solid when such a formulation is used. This matrix relates the stresses at the collocation points arising from the applled loads (including those applied to the crack surfaces) to the values of the opening of the crack at the integration points. The method relles on the numerical procedure developed by Gerasoulis (ref. 1). Which is used to reduce equation (1) to a system of algebraic equations for unknown values of $f(t)$ at discrete points in the interval $[-1,1]$.

FORMULATION

The algorithm is best explatned through a simple example. For the cracked plate: shown in figure 1 the governing equations for the dislocation density are 


$$
\begin{gathered}
\frac{2 \mu}{\pi(x+1)} \int_{-1}^{1} \frac{f(t) d t}{t-x}=\sigma_{\infty}-1<x<1 \\
\int_{-1}^{1} f(t) d t=0
\end{gathered}
$$

where $\mu$ is the shear modulus, $k=3-4 v$ for plane strain, and $v$ is Poisson's ratio.

The crack opening displacement is given by

$$
u^{+}-u^{-}=x^{1} f(t) d t
$$

The exact solution to this problem is

$$
\begin{aligned}
& f(x)=\sigma_{\infty} \frac{(k+1)\left(1-x^{2}\right)^{-1 / 2} x}{2 \mu} \\
& u^{+}-u^{-}=\sigma_{\infty} \frac{(x+1)\left(1-x^{2}\right)^{1 / 2}}{2 \mu}
\end{aligned}
$$

Following [1], (after nondimensionalizing by setting $2 \mu / \pi \sigma_{\infty}(\kappa+1)$ equal to unity), $f(t)$ is expressed by

$$
f(t)=\phi(t)\left(i-t^{2}\right)^{-1 / 2}
$$

and $\phi(t)$ is approximated as piecewise quadratic in $[-1,1]$. The result is that equations (3) and (4) are reduced to a system of algebraic equations through quadrature formulas. The detalls of the quadrature can be found in reference 1 and are omitted here. The results are

$$
\begin{gathered}
\sum_{i=1}^{2 N+1} w_{i}\left(x_{k}\right) \phi\left(t_{i}\right)=1 \quad k=1,2 N \\
\sum_{i=1}^{2 N+1} v_{i} \phi\left(t_{i}\right)=0
\end{gathered}
$$

We note that the unknown values $\phi$ are those at the integration points $t_{1}$, while the stresses on the right hand side of equation (9) are at the collocation points $x_{k}$.

For 111 ustration we take five points for the quadrature, and equations (9) and (10) become 


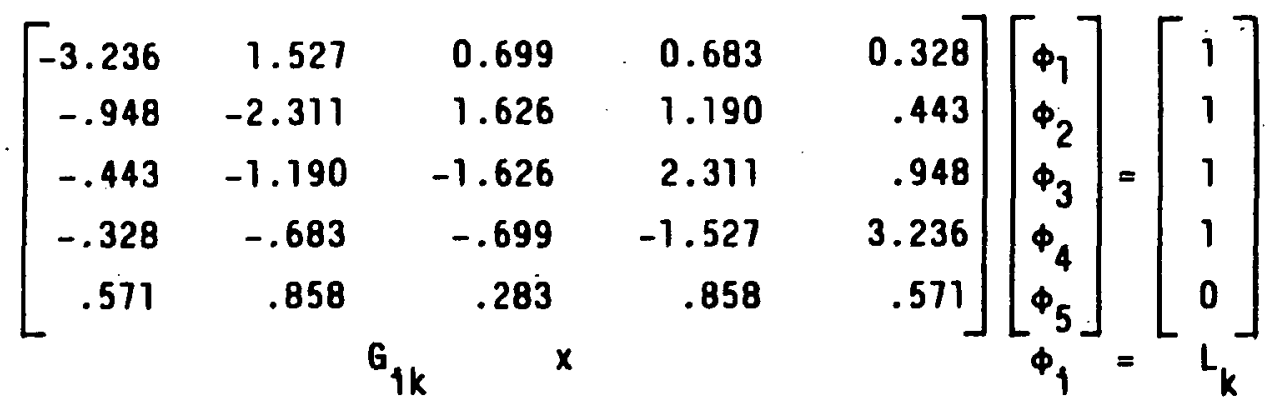

In equation (11), matrix $G$ is characteristic of the geometry of the problem and matrix $L$ represents the loading and crack closure condition. What is usually of interest in such a problem is the stress intensity factor, and since the stress intensity factor is proportional to the value of $\phi$ at the endpoints (ref. 1), equation (11) is solved for the unknown vector $\phi$.

Instead of doing this, in this paper the inverse of matrix $G$ is obtained, and the product of this matrix and $\left(1-t^{2}\right)-1 / 2$ is integrated term by term to obtain a matrix $C$ which is called the compliance matrix for this particular geometry. The integration of each term is performed using the weights for the Lagrange interpolation polynomials, since the function $\phi$ is approximated in this manner. The results of the integration lead to the following

$$
\left[\begin{array}{rrrr}
0.000 & 0.000 & 0.000 & 0.000 \\
.087 & .121 & .049 & .019 \\
.029 & .130 & .130 & .029 \\
.019 & .049 & .121 & .087 \\
.000 & .000 & .000 & .000
\end{array}\right]\left[\begin{array}{l}
1 \\
1 \\
1 \\
1
\end{array}\right]=\left[\begin{array}{l}
\left(u^{+}-u^{-}\right)_{1} \\
\left(u^{+}-u^{-}\right)_{2} \\
\left(u^{+}-u^{-}\right)_{3} \\
\left(u^{+}-u^{-}\right)_{4} \\
\left(u^{+}-u^{-}\right)_{5}
\end{array}\right]
$$

We note that matrix $C$ is not a square matrix. This is because the number of integration points is one more than the number of collocation points. Matrix $C_{\text {ik }}$ relates the displacement of the crack faces at the point $t_{1}$ to the stress at point $x_{k}$.

For the present problem the applied loading vector is unity, and premultiplying it by the compliance matrix leads to

$$
\begin{aligned}
& \left(u^{+}-u^{-}\right)_{1}=0.0 \\
& \left(u^{+}-u^{-}\right)_{2}=0.276 \\
& \left(u^{+}-u^{-}\right)_{3}=0.318 \\
& \left(u^{+}-u^{-}\right)_{4}=0.276 \\
& \left(u^{+}-u^{-}\right)_{5}=0.0
\end{aligned}
$$

The above displacements agree with the exact solution. 
The usefulness of the compliance matrix becomes evident when one is interested in investigating the effects of many loading cases, and in particular, if the stresses along the crack surfaces depend on the crack opening displacements. Such loadings are used in models for flber reinforced concrete, rocks, ceramics, and other materials where microcracking, fiber bridging, and other nonlinear effects are modeled as nonlinear springs along the crack surfaces (refs. 2 to 5). For these models equation (1) becomes nonlinear, and an iterative solution is needed. With the use of the compliance matrix, this iteration procedure is efficlent and fast.

As an example, let us assume that the crack surfaces are bridged by fibers, and that the stresses transmitted by the fibers to the crack depend on the opening of the crack. The displacements along the crack will be governed by

$$
\left(u^{+}-u^{-}\right)_{t_{1}}=c_{1 k} \times\left[\sigma_{x_{k}}(\text { applied loads })+\sigma_{x_{k}}\left(u^{+}-u^{-}\right)\right]
$$

where now the stresses are decomposed into those arising from the applied loads, and those due to the flber bridging. The function o( $\left.u^{+}-u^{-}\right)$is determined from experiments (ref. 6). For the first iteration the stresses due to fiber bridging are assumed to be equal to zero. Premultiplying the stresses arising from the applied loading by the compliance matrix results in the first approximation to the crack opening displacements. From these displacements the first approximation to the fiber bridging stresses are determined, and these are applied to the crack surfaces. The procedure is repeated unt 11 convergence is reached. This procedure was used in reference 4 (where experiments performed on concrete and fiber reinforced concrete were analyzed) and convergence was observed to be very fast (only several iterations were needed for three and four point bending specimens).

\section{CONCLUSIONS}

An algorithm has been presented which can be used to develop compliance matrices for cracked bodies. The usefulness of the matrices becomes evident when one is interested in performing parameter studies to investigate the effects of various loadings on crack opening displacements. Even though the example presented in this paper involved Mode-I loading, the method can be extended to include mixed mode problems (including three-dimensional problems).

\section{REFERENCES}

1. Gerasoulis, A.: The Use of Plecewtse Quadratic Polynomials for the Solution of Singular Integral Equations of Cauchy Type. Comput. Math. App 1., vol. 8, no. 1, 1982, Pp. 15-22.

2. Keer, L.M.; and Meade, K.P.: A Note on a No-Silp Interface Crack, J. Appl. Mech., vol. 49, no. 2, June 1982, Pp. 454-455.

3. Wecharatana, M.: and Shah, S.P.: A Model for Predicting Fracture Resistance of Fiber Reinforced Concrete. Cem. Concr. Res., vol. 13, no. 6, Nov. 1983, pp. 819-829. 
4. Ballarin1, R.; Shah, S.P.; and Keer, L.M.: Crack Growth in Cement Based Composttes, Engineering Fracture Mechanics, vol. 20, no. 3, 1984, Pp. $433-445$.

5. Catalano, D.M.; and Ingraffea, A.R.: Concrete Fracture: A Linear Elastic Fracture Mechanics Approach, Report No. 82-1, Dept. of Structural Engineering, Cornell University, 1982.

6. Shah, S.P.: Stroeven, P.; Dalhutsen, D.; van Stekelenberg, P.: Complete Stress-Strain Curves for Steel Fiber Reinforced Concrete in Uniaxial Tension and Compression. Proc. Int. Symp., RILEM-ACI-ASTM, Sheffield, 1978, pp. 339-408. 


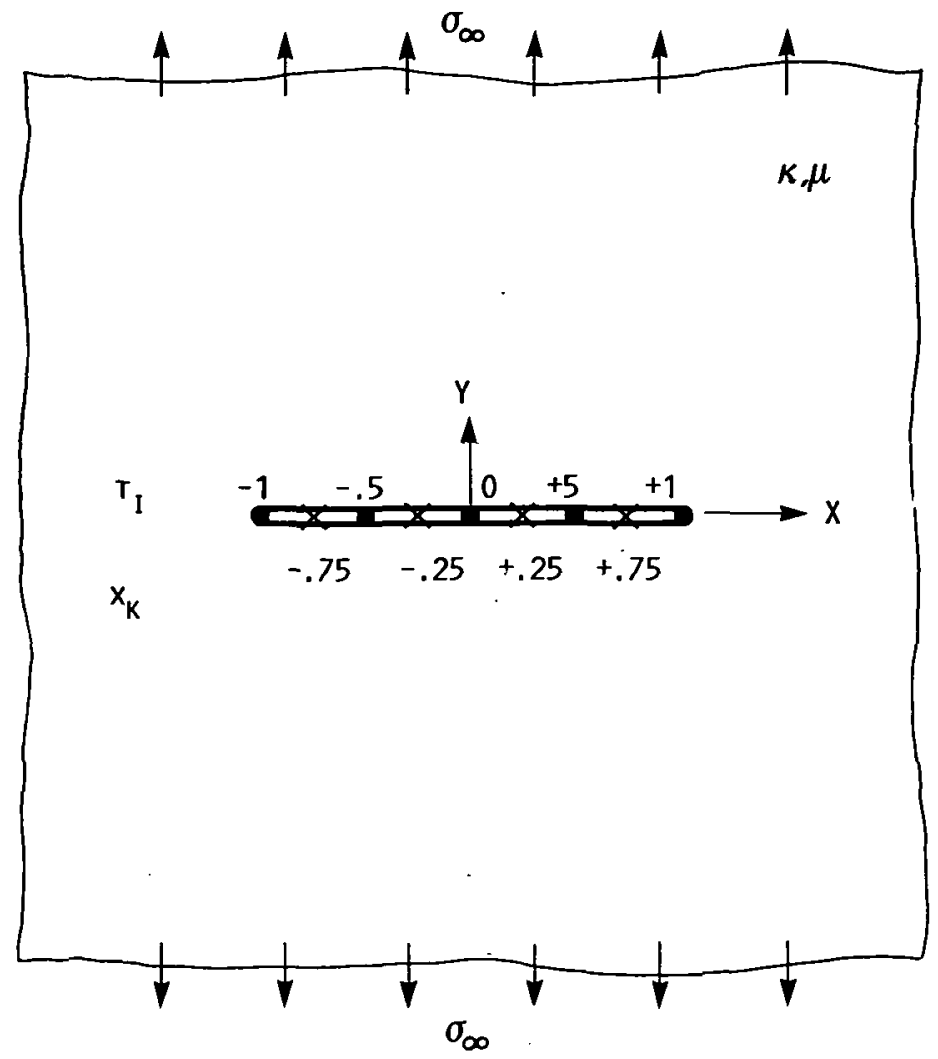

Figure 1.- CRACKed PLATE SHOWING integration and COllocation POINTS FOR FIVE POINT QUADRATURE. 


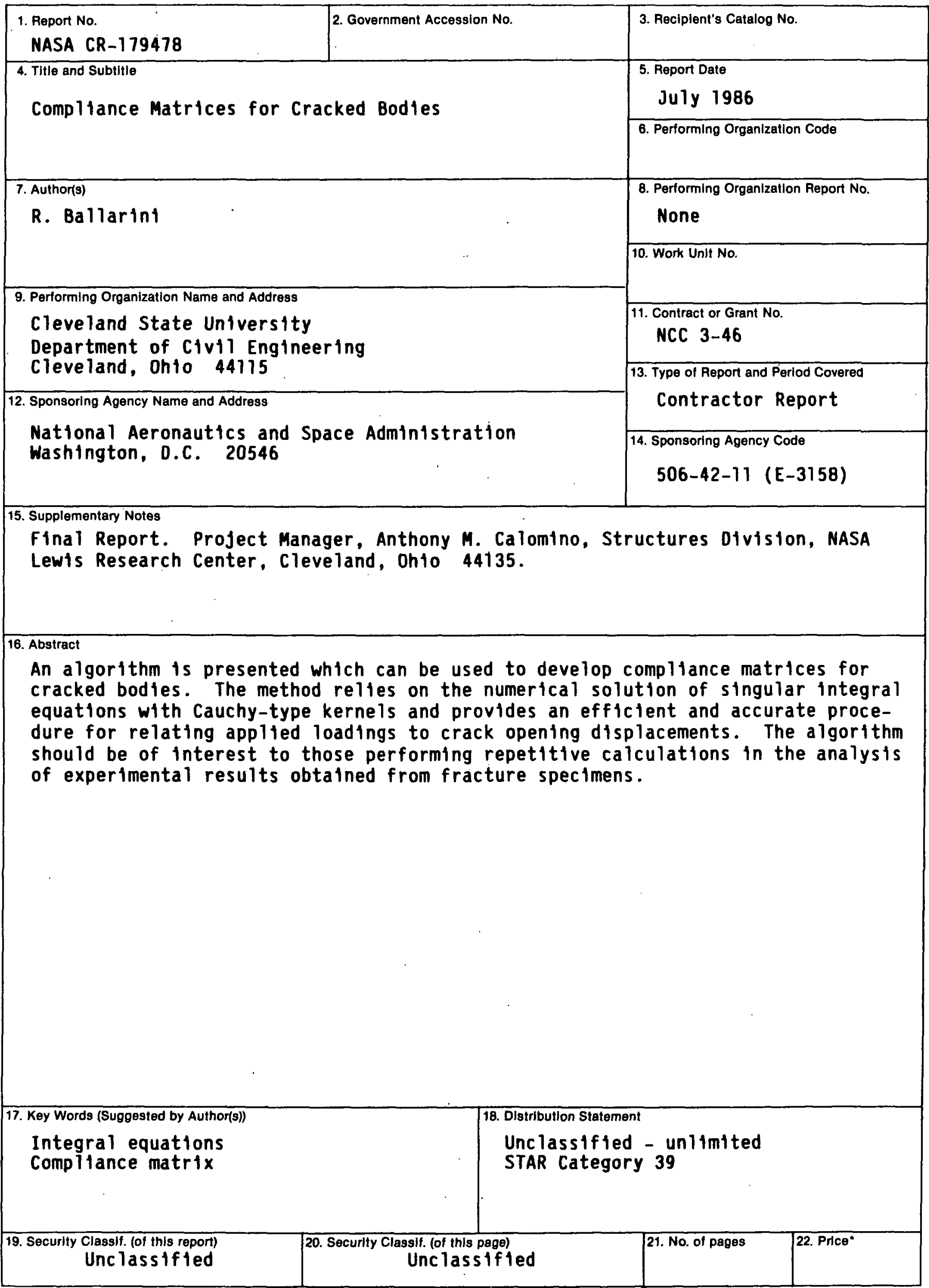

"For sale by the Natlonal Technical Information Service, Springfield, Virginia 22161 
National Aeronautics and

Space Administration

Lewis Research Center

Cleveland, Ohio 44135

Official Business

Penalty for Pitvate Uso $\$ 300$
ADDRESS CORRECTION REQUESTED National Aeronautics and

Space Administration

NASA-451 